\title{
‘60-20 Emission’ - The unequal distribution of greenhouse gas emissions from personal, non-business travel in the UK
}

\section{Authors and affiliations:}

Dr Christian Brand ${ }^{a}$ and Prof John M. Preston ${ }^{b}$

${ }^{a}$ Transport Studies Unit, Oxford University Centre for the Environment, South Parks Road, Oxford, OX1 3QY, UK. Email: christian.brand@ ouce.ox.ac.uk, Tel: +44 (0)1865 285177, Fax: +44 (0)1865 275850 (corresponding author)

${ }^{\mathrm{b}}$ Transportation Research Group, School of Civil Engineering and the Environment, University of Southampton, Highfield, Southampton, SO17 1BJ, UK. Email:

J.M.Preston@ soton.ac.uk, Tel: +44 (0) 238059 4660, Fax: +44 (0) 2380593152

Note: this is a personal version, created by Christian Brand, of the text of the accepted journal article. It reflects all changes made in the peer review process, but does not incorporate any minor modifications made at the proof stage. The complete citation for the final journal article is:

- Brand, C., Preston, J.M., 2010. '60-20 emission' - The unequal distribution of greenhouse gas emissions from personal, non-business travel in the UK. Transport Policy 17, 9-19.

- DOI: http://dx.doi.org/10.1016/j.tranpol.2009.09.001

Copyright $(\subseteq$ and Moral Rights for this paper are retained by the individual authors and/or other copyright owners 


\begin{abstract}
Relatively little is known about the composition of greenhouse gas emissions from personal, non-business travel at the disaggregate levels. This paper aims to give insights into the distribution of emissions amongst the UK population. When including non-carbon climate effects air travel dominates overall greenhouse gas emissions. There is a huge range in emissions, with the highest $20 \%$ of emitters producing $61 \%$ of emissions. This ' $60-20$ emission' rule is surprisingly similar across units and scale of the analysis. Disaggregated data tell a different story than aggregated data. While income, working status, age and car ownership are significantly related to overall emissions, factors related to accessibility, household location and gender are not.
\end{abstract}

\title{
ACKNOWLEDGMENTS
}

This paper stems from research funded by the UK Economic and Social Research Council with additional funding from the Environmental Change Institute at Oxford University. The views expressed by this paper remain those of the author and do not necessarily reflect those of the main funders.

Keywords: travel behaviour; $\mathrm{CO}_{2}$; greenhouse gases; emissions distribution; air travel; car travel 


\section{BACKGROUND AND AIMS}

Transport poses a major challenge as a main contributor to climate change and its underlying causes, mainly emissions of anthropogenic greenhouse gases (GHG) into the atmosphere. Carbon dioxide $\left(\mathrm{CO}_{2}\right)$ is the greenhouse gas that contributes most to global climate change. Its emissions from transport are rising across the globe, and the United Kingdom (UK) is no exception. In 2005, the transport sector accounted for $24 \%$ of total $\mathrm{CO}_{2}$ emissions in the UK. It is the only sector of the UK economy for which current $\mathrm{CO}_{2}$ emissions are higher than in 1990 (DEFRA, 2006). $\mathrm{CO}_{2}$ emissions from domestic, non-military transport activities were 117 million tonnes of $\mathrm{CO}_{2}$ in 1990 and 129 million tonnes in 2005, a 10\% increase (Jackson et al., 2007). While emissions from road transport increased by $9 \%$ (from 110 million tonnes of $\mathrm{CO}_{2}$ to 120 million tonnes), emissions from domestic civil aviation nearly doubled over the same period (from 0.62 million tonnes to 1.19 million tonnes). In terms of passenger travel, $\mathrm{CO}_{2}$ emissions from domestic travel by cars, taxis, motorcycles, buses, rail (from diesel operation only) and civil aviation in 2005 were 86 million tonnes, representing $66 \%$ of UK domestic transport emissions (DfT, 2008b). On top, international air travel accounted for about 35 million tonnes. So when including international air travel car and air travel dominate passenger transport emissions at $64 \%$ and $29 \%$ respectively - leaving $7 \%$ to be divided among the rest. The figure for international aviation is based on fuel consumption from international bunkers and hence includes emissions for the outward flight only - an important issue that will be discussed later in this paper.

A lot of effort is put into estimating emissions figures at the aggregate levels, yet surprisingly little is known about the GHG profile of the population, which segments of the population are contributing most to the problem, and the extent to which different groups of the population will be affected by any responses to the problem. Research by, for example, Hillman and Walley (1983), Banister (1993), Hughes (1994), Greening et al. (1997), Anable et al. (1997), and more recently Institute of Public Policy Research (IPPR, 2003) and Greening (2004) identify that different subgroups in the population, described by various socioeconomic, demographic and other personal characteristics, have different levels of emissions from personal motorised transportation.

In the absence of direct measurement of GHG emissions it is often necessary to examine either fuel consumption or travel activity and derive emissions from that. Travel activity varies by a number of factors. For instance, people in households with access to a car make more trips and travel further than those without access. Car access and income are also strongly related (DfT, 2003). Thus, income is a factor relating to the number of trips and distance travelled. In 2006, people in the highest income quintile did nearly $30 \%$ more trips than those in the lowest income quintile and travelled nearly three times further (ONS, 2007). In particular, those in the highest income group did twice as many trips and travelled over three times further by car than those in the lowest income quintile group. Rail use is much higher in the highest income quintile, partly because commuters to London in the highest 
income band account for a considerable proportion of rail travel. The UK has the highest air travel per head in Europe, with a fifth of international flights passing through UK airports. According to the UK Civil Aviation Authority, passenger numbers at UK airports have been growing at about $6 \%$ per year since the mid-1970s - more than twice the rate of economic growth - and show no sign of slowing. The UK's share is calculated by allocating emissions from half the flights to and from UK airports to the UK, but more than half of these flights are by UK citizens. Most of the increase in UK flights has come from wealthier individuals flying more. Trips by those in the lower-income bands fell between 2000 and 2004 (Cairns and Newson, 2006). Even with cheap flights on low cost airlines, foreign holidays remain too expensive for those on low incomes. The average household income of UK leisure passengers travelling through Stansted airport was $£ 51,000$ in 2005, compared with an average household income of $£ 31,000$ (CAA, 2005). The majority of the research evidence confirms the significance of the link between income and the demand for air travel (e.g. Brons et al., 2002; Korbetis et al., 2006).

Further to income, travel patterns also vary according to demographics, other socioeconomic aspects (e.g. gender, age, working status), private vehicle ownership, ethnicity and culture (e.g. Best and Lanzendorf, 2005; Carlsson-Kanyama and Linden, 1999; Lee and McNally, 2003; Stead, 1999; Susilo and Stead, 2007). Travel patterns and behaviour also vary according to environmental consciousness, energy costs (Fox, 1995; Nilsson and Kuller, 2000) as well as chosen lifestyles, personal preferences, worldviews and attitudes (Anable, 2005).

This social variability of travel activity is rarely translated into a GHG distribution at the individual and household levels. A bottom-up analysis and comparison across all modes of travel is lacking for the UK. This lack of appropriate data makes policy development difficult.

The goal of this paper is thus to profile personal, non-business related travel activity and associated GHG emissions across all modes of personal passenger travel (i.e. not freight, not military, not in course of business) by presenting results of recently completed primary research on a sample population in the UK. The main research questions were: what is the distribution of emissions? Is there an association between emissions and personal characteristics of the population? If so, how strong is this association? How strong is it between air travel emissions and income, age and/or household location? Between car travel emissions and gender and/or car ownership? Between public transport travel emissions and car ownership, income, age, household location and or accessibility to bus or rail stations?

The paper contributes to the debate on what factors influence personal travel emissions contributing to climate change. The detailed analysis of the variability between individuals and households fills evidence gaps in the literature.

The paper begins by outlining the methodology used to collect disaggregate travel behaviour and emissions data on a sample population of UK residents. GHG emissions are then examined at the household and individual levels as to how they vary (or not) with respect to geographical location, socio-demographic factors, car ownership, accessibility and other personal characteristics. The paper concludes by discussing the implications for those responsible for the design of GHG emissions reduction policies. 


\section{APPROACH}

\subsection{Overall approach}

To explore the variation of travel emissions and derive disaggregate emissions profiles, a substantive case study involving random and targeted samples of the population of Oxfordshire, a region located in the South East of England was undertaken. The empirical research employed three stages of data collection, preparation and analysis. First, a household survey technique based on weekly and annual estimates of personal, non-business travel activity was used to collect the data required to measure the key determinants of GHG emissions from travel. A mixed-method approach using triangulation techniques was employed to gain insights into what method works best, validate internally and improve accuracy of the final outputs.

Secondly, a computational evaluation tool was developed, which was designed to incorporate travel activity data with emission rates for each GHG pollutant for a range of transport modes, vehicle characteristics, travel characteristics, times of day and operating conditions. Secondary data were collected for this stage, including local emissions factors, fuel lifecycle emissions and public transport passenger loadings.

Thirdly, the travel activity data were translated into emissions profiles, analysed at the individual and household levels and aggregated to higher levels. This included internal validation by comparing alternative techniques and external validation in terms of comparison and triangulation with more aggregate datasets and national statistics.

\subsection{The household travel survey: design, sampling and implementation}

The household survey was designed to collect annual travel activity data from two main study groups (the household and, separately, all individuals aged 6 years or older), within which examination was made of how household location, structure, income, occupation, age, gender, vehicle ownership, choice of transport mode and access to services and public transport may affect travel emissions. This used elements of travel behaviour surveys employing the well tested travel diary approach (e.g. Brög et al., 2004; ONS, 2007). However, given the much longer target timeframe, the survey was redesigned and adopted from survey work first trialled by Anable et al. (1997).

Two versions of the survey questionnaire were developed, piloted (with 21 university staff and their families) and then employed on a larger scale: a postal paper-and-pen version and a web-based version. Both versions included a number of forms asking details of household structure and socio-economic background; simple accessibility data; details on regular daily/weekly travel and irregular, casual travel by public transport, walking and cycling; vehicle-specific data (such as fuel type and recorded or estimated annual distance travelled) as well as vehicle use data for each driver in the household. 
The survey sampling involved two sampling methods that were matched with the two types of survey. First, simple random sampling was used for the postal survey, based on a complete listing of every private household address in Oxfordshire obtained from the Ordnance Survey Postal Address File (PAF). Based on the socio-economic characteristics of the respondents of the postal survey, targeted non-random sampling was used for the webbased survey to target underrepresented segments of the population (e.g. young male workers, students living in college halls). The postal, pen-and-paper questionnaires were sent out to 900 households. To stimulate higher response rates, it was administered with pre-paid return envelopes and a prize draw. Reminder procedures were used to chase non-respondents after two weeks of the initial mail-out.

\subsection{The survey sample}

The paper-and-pen survey achieved a response of 171 out of 900 completed household returns (19\%), providing 339 individual travel profiles. In addition, the web-based survey achieved a response of 117 out of 532 completed individual returns (22\%). This provided a total sample size of 456 individuals living at 278 addresses. Of these, $72 \%$ of individuals held a driving licence, 59\% drove cars and/or motorcycles, 59\% made at least one flight over the year, 69\% had used buses or coaches, $46 \%$ taxis, $52 \%$ rail and $15 \%$ ferry. Some $20 \%$ of respondents (91 out of 456) drove but didn't fly, while incidentally the same number (but not necessarily the same sub-sample) of respondents didn't drive but flew at least once. Interestingly, nearly two fifth (178) did both, and one fifth (96) did neither.

The relatively low response rate is likely to be caused by the length of the questionnaire; a head of household of a family of 4 with 2 cars and 2 return flights a year had to fill in 3 separate forms on 19 pages of A4 paper. He/she could easily have spend 40 minutes filling this in. This is obviously a limitation in terms of response rates. The choices of approach and techniques used will always be a balance between accuracy and the need for detailed descriptions of disaggregate travel patterns, cost-effectiveness of the survey instrument (i.e. reasonable response rates and cost per response) and resource constraints. For this research it was decided to aim for accuracy and detailed descriptions of disaggregate travel patterns that allowed internal consistency and integrity checks, at the expense of a lower response rate. Crucially, however, the achieved sample size of nearly 500 individual responses still allows for meaningful statistical analysis, no matter what the response rate was.

The comparison of the socio-economic composition of the sample with UK Census data for the region showed that the sample was representative of the regional population in terms of age structure, gender and working status - all within 5\% of each other. For instance, the sample included 53\% of respondents that were 'economically active' (i.e. working, in full time education, between 16 and 74 years of age), compared to $52 \%$ for the region. The sample had 53\% female respondents, compared to 51\% in the sample. Among the respondents, there was some over-representation of individuals of pensionable age, while 36-50 year olds are slightly underrepresented (both within $5 \%$ of each other though). Car ownership was $2 \%$ lower 
in the sample than regional figures. Despite the degree of accuracy of representation, the results presented in this paper have been weighted for response bias by gender, age and working status.

\subsection{Assessment and evaluation of greenhouse gas emissions}

GHG emissions are expressed throughout this paper as mass of $\mathrm{CO}_{2}{ }^{\mathrm{eq}} \cdot \mathrm{CO}_{2}{ }^{\mathrm{eq}}$ is a metric used to compare the emissions of greenhouse gases based upon their 100-year Global Warming Potential (GWP) used by the Intergovernmental Panel on Climate Change (IPCC: Houghton et al., 2001), with respective 100-year GWP of 23 and 296 for $\mathrm{CH}_{4}$ and $\mathrm{N}_{2} \mathrm{O}$ expressed in terms of $\mathrm{CO}_{2}$. The one exception is air travel, where GWP cannot be used and no comparative metric currently exists (Shine et al., 2005; Wit et al., 2005).

Total GHG emissions $\left(\mathrm{CO}_{2}{ }^{\text {eq,tot }}\right)$ are the sum of direct emissions of $\mathrm{CO}_{2}\left(\mathrm{CO}_{2}{ }^{\text {dir }}\right)$ (e.g. car and bus exhaust emissions when in use, including $\mathrm{CO}_{2}$ and other pollutants in the exhaust mix that have the potential to form $\mathrm{CO}_{2}$ in the atmosphere); direct emissions of non- $\mathrm{CO}_{2} \mathrm{GHG}$ $\left(\mathrm{CO}_{2}{ }^{\text {eq,non-CO2}}\right.$ ) (expressed as $\mathrm{CO}_{2}$ equivalent using an 'impact metric' or 'impact weighting factor', depending on mode of transport); and indirect emissions of $\mathrm{CO}_{2}$ and non- $\mathrm{CO}_{2} \mathrm{GHG}$ $\left(\mathrm{CO}_{2}{ }^{\text {eq,ind }}\right)$ (i.e. the $\mathrm{CO}_{2}$ equivalent of upstream emissions during fuel production and delivery). For the surface transport modes, total GHG emissions take the simple equation (all in mass of pollutant, e.g. kg or tonne):

$$
\mathrm{CO}_{2}^{\text {eq,tot }}=\mathrm{CO}_{2}^{\text {dir }}+\mathrm{CO}_{2}^{\text {eq,non-CO2 }}+\mathrm{CO}_{2}^{\text {eq,ind }}
$$

with

$$
\begin{array}{ll}
\mathrm{CO}_{2}^{\text {eq,non-CO2 }}=23 \times \mathrm{CH}_{4}^{\text {dir }}+296 \times \mathrm{N}_{2} \mathrm{O}^{\text {dir }} & \text { (E1b) and } \\
\mathrm{CO}_{2}^{\text {eq,ind }}=\mathrm{CO}_{2}^{\text {ind }}+23 \times \mathrm{CH}_{4}^{\text {ind }}+296 \times \mathrm{N}_{2} \mathrm{O}^{\text {ind }} & \text { (E1c). }
\end{array}
$$

GHG emissions from air travel are treated differently because emissions at higher altitudes can instigate a host of chemical and physical processes that have climate change consequences. Higher altitudes are typically reached for flight distances of more than 700 kilometres (DLR, 2000). To make a more general assessment of relative emissions impacts, this research applies the Precautionary Principle (UNCED, 1992) in using an alternative 'weighting' coined the Aviation Impacts Multiplier (AIM), with values based on the most up-to-date figures for the Global Temperature Potential metric (between 1.5 and 3, with central value of 2, according to Wit et al., 2005) and the most recently the TRADEOFF project (Sausen, 2005) which suggests a metric of 1.9. For the purposes of this paper, the new multiplier is represented by low (1.5), central (3) and high (4) values. This can be considered to be a reasonable range as the latest estimates for the radiative forcing of aviation do not include the climate effects of cirrus cloud formation, believed to have potentially significant effects (Sausen, 2005). While equations E1a and E1c stay the same, equation E1b takes a slightly different form for calculating $\mathrm{CO}_{2}{ }^{\text {eq,tot }}$ emissions from air travel:

$$
\mathrm{CO}_{2}^{\text {eq,non-CO2}}=(A I M-1) \times C \mathrm{O}_{2}^{\text {dir }}
$$

where, 
$A I M=1.5$ (low), 3 (central) or 4 (high) for (flight distance) $>700 \mathrm{~km}$ and $A I M=1$ for (flight distance) $\leq 700 \mathrm{~km}$.

The assessment of GHG emissions is performed by employing a number of techniques and data sources, which differ by mode of transport. The calculating of emissions was mainly based on the well tested methods of either assessing travel activity and multiplying by emissions rates or assessing fuel consumption directly and multiplying by the carbon content of the fuel (see e.g. Barlow et al., 2001; EEA, 2000). This builds on the experience gained in previous work undertaken at the University of Oxford (Anable et al., 1997; Brand and Preston, 2003; Jardine, 2005); aggregate European emissions models such as STEEDS (Brand et al., 2002), COPERT (EEA, 2000; Ntziachristos and Samaras, 1997), TRENDS (EC, 2002) and TREMOVE (De Ceuster et al., 2004); other emissions factor databases, e.g. UK specific inventories (Barlow et al., 2001; NETCEN, 2003; VCA, 1996); and complementary methods on air travel (e.g. CfIT, 2001; EC, 2002; FAR and Germanwatch, 2005).

For car travel, four alternative techniques were developed and employed to derive GHG emissions. The main method, henceforth called method 'A', calculates emissions from equations relating GHG pollutant emissions (carbon dioxide, $\mathrm{CO}_{2}$, methane, $\mathrm{CH}_{4}$ and nitrous oxide, $\mathrm{N}_{2} \mathrm{O}$ ) to 3 fuel types, 3 engine sizes, age (with Euro emissions standards as the proxy), 3 trip lengths and 3 road types (with average speeds as the proxy) based on the set of speedemission equations (Barlow et al., 2001). To be consistent between methods, this includes excess emissions from cold starts (taking into account the shares of urban vs. non-urban driving) as well as 'well-to-tank' emissions from fuel production based on the most recent update of the European Well-to-Wheels study (JRC and CONCAWE EUCAR, 2006).

The main method for bus, rail, taxi and ferry travel was based on transport activity (split into 'day-to-day' and 'casual' travel, with an indication of peak or off-peak travel), vehicle emissions factors and passenger loadings per vehicle. Two different sets of emissions factors and occupancy rates were used: one national and the other local/regional (DfT, 2006b; Go Ahead, 2005).

For air travel, two alternative techniques were used - one based on trip distance and one on trip duration as the main primary data source. Total annual emissions are derived using a two-step approach. First, top level travel activity indicators (distance travelled, time spent in the air) are derived from data collected in the surveys for each flight (each leg, both directions, including stopovers). Secondly, the travel indicators are multiplied by emissions factors based on distance-emissions curves developed for this research. These distance-emissions curves were derived from market-share average-weighted fuel consumptions of seven of the most common aircraft types obtained from European Environment Agency (EEA, 2005), which were further split into two distance classes (short-haul and long-haul, defined as below or above 3,500 km flight distance). Crucially, as the total distance includes all legs of a journey (single or return-out and return-back), so do the emissions totals include all legs, independent of where the aircraft was refuelled. This is fundamentally different to most national accounts where only either the outbound or the inbound leg is accounted for. 
In addition, the methodology takes account of the most important factors influencing fuel consumption, including the number of take-offs per trip, average passenger loadings, cargo factors (which reduce average emissions per passenger-km by about $2 \%$ ), detours and holding patterns obtained from a number of sources (e.g. AEA, 2002; CAA, 2006; DLR, 2000). The various techniques and emissions factors are described in detail in Brand (2008).

Average emissions per driver- or passenger-km are shown in Figure 1, based on the population sample and the main methods for calculating emissions. The Figure also shows the range of values (error bars show minimum and maximum of values for the sample, not uncertainty ranges) emerging from the emissions calculations. Note the air travel emissions rates include the aviation impacts multiplier of 3 for all flights that are further than $700 \mathrm{~km}$.

Figure 1: Average emissions of greenhouse gases for the sample population (in $\mathrm{CO}_{2}{ }^{\mathrm{eq}}$ per $\mathrm{km}$ )

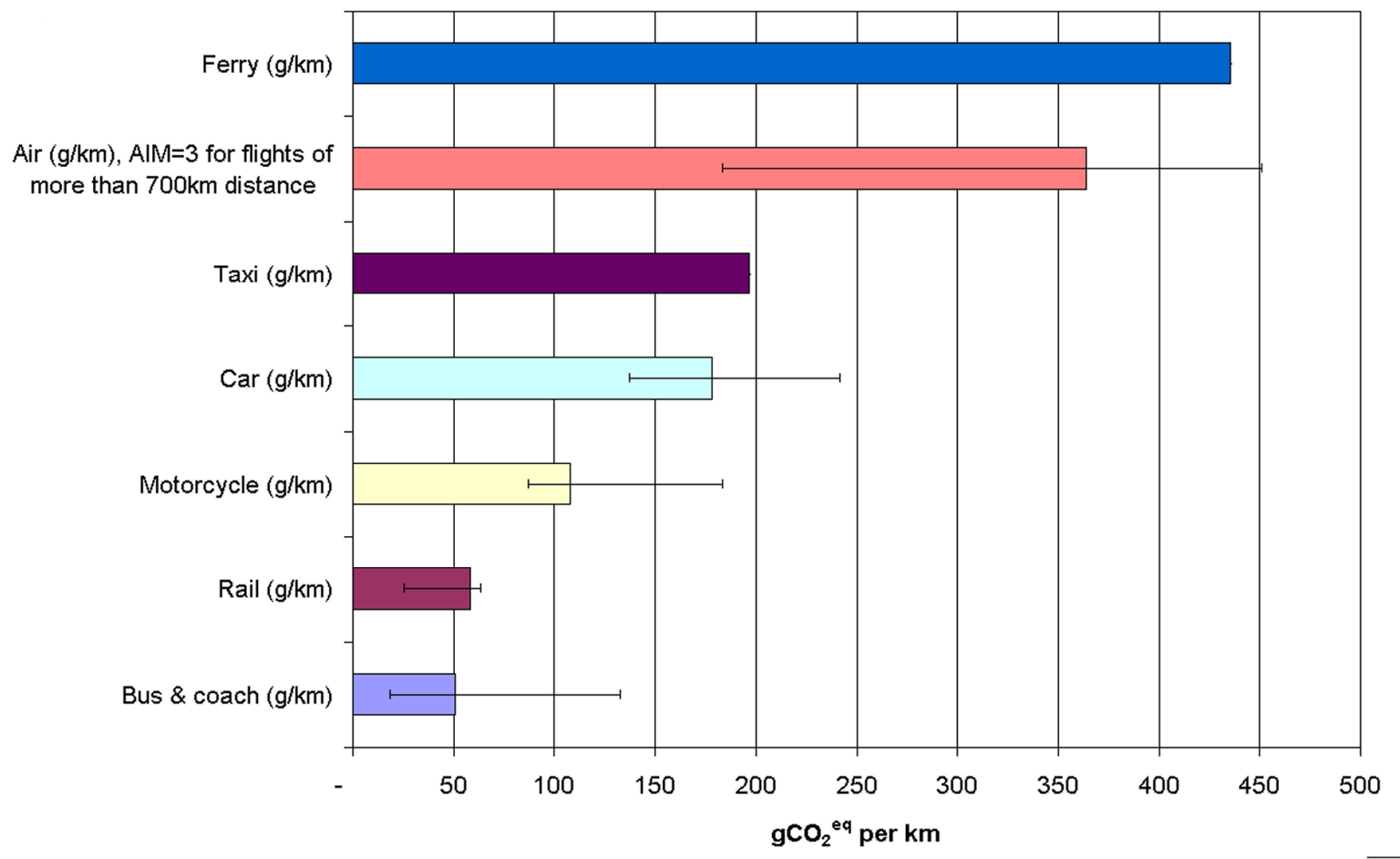

Base: all respondents who travelled by the various modes, e.g. 269 fliers, 266 car drivers.

The error bars indicate the minimum and maximum values for the sample population, a direct result of the different methods used for the different modes. These are not uncertainty estimates but highlight the range of values attained.

\section{TRAVEL EMISSIONS PROFILES}

\subsection{Area-wide travel emissions profiles}

The achieved sample size allowed for a distinction to be made between a number of geographical area types whilst ensuring statistically significant results for each. Four geographical area types based on built-up/non-built area and population characteristics were defined for the analysis: 'large urban' (built-up, population 100-250k); 'medium urban' (built- 
up, population 25-100k); 'small urban' (built-up, population 10-25k); and 'rural' (non built-up, population $<10 \mathrm{k}$ ). While responses came mostly from households in large urban areas (194 individuals), none of the area types had responses of less than 64.

\subsubsection{Travel activity}

Not surprisingly, travel by air and car dominates total distance travelled, accounting for $77 \%$ of total annual kilometres. For air travel, the flying individuals (59\% of the sample) averaged an astonishing 17,400 air-kilometres, 24 airborne hours and 5.4 landing and take-offs (LTO) per person p.a. Most fliers took off about twice a year while a small proportion flew a lot more - up to 13 return trips in one year. Respondents living in medium and large urban areas travelled less by car and air (73\%) than respondents living in small and rural areas (87\%). Specifically, the distances travelled by car by Oxford residents were 27\% lower than the sample average while residents in rural areas travelled on average $46 \%$ further than the sample average. Conversely, Oxford residents travelled $31 \%$ further by air than the sample average, whereas the distances travelled by air of residents in small urban and rural areas were $23 \%$ and $30 \%$ lower than the sample average. For respondents living in large and medium urban areas, travel by public transport (rail, bus, coach, taxi) was significantly higher than the national average, reflecting the location of Oxford City and its surrounding towns in London's commuter belt and, for UK standards, the good provision of public transport services in central Oxfordshire.

\subsubsection{Travel emissions}

This travel activity translated into average GHG emissions of 5.2 tonnes of $\mathrm{CO}_{2}$ equivalent $\left(\mathrm{tCO}_{2}{ }^{\text {eq,tot }}\right.$ ) per person per year (all modes, method ' $\mathrm{A}$ ' for car, method ' $\mathrm{E}$ ' for air, central value of 3 for AIM as defined earlier). Private travel by air (70.2\%) dominates GHG emissions from personal travel activity, partly because of the inclusion of non- $\mathrm{CO}_{2}$ climate effects in the analysis. Interestingly, when looking at emissions of $\mathrm{CO}_{2}$ alone - thus excluding non- $\mathrm{CO}_{2}$ climate effects - emissions from air travel were still high (49\% of total), roughly on a par with car travel (44\%). All other modes (rail, bus, taxi, motorcycles, ferry) made up only $7 \%$ of the $\mathrm{CO}_{2}$ total. Table 1 provides total and average GHG emissions by mode of transport and geographical area. 
Table 1: Total and average greenhouse gas emissions $\left(\mathrm{CO}_{2}{ }^{\text {eq,tot }}\right)$ by mode of transport and geographical area

\begin{tabular}{|c|c|c|c|c|c|c|c|c|}
\hline & \multicolumn{8}{|c|}{$\mathrm{CO}_{2}{ }^{\text {eq,tot }}$ emissions (kg p.a.) } \\
\hline Mode & $\operatorname{Car}^{1}$ & $\begin{array}{c}\text { Motorcy } \\
\text { cle }\end{array}$ & $B u s^{2}$ & Rail & Taxi & Ferry & $A i r^{3}$ & Total \\
\hline Survey total ('000) & 608 & 7 & 29 & 46 & 7 & 12 & 1,672 & 2,381 \\
\hline Individual average $^{4}$ & 1,333 & 16 & 64 & 101 & 14 & 26 & 3,667 & 5,222 \\
\hline - Large urban & 984 & 1 & 98 & 145 & 17 & 27 & 4,811 & 6,083 \\
\hline - Medium urban & 1,345 & 35 & 38 & 131 & 19 & 31 & 3,113 & 4,712 \\
\hline - Small urban & 1,432 & 7 & 36 & 33 & 5 & 3 & 2,783 & 4,299 \\
\hline - Rural & 1,875 & 31 & 43 & 42 & 13 & 32 & 2,611 & 4,648 \\
\hline South East average ${ }^{6}$ & 1,248 & 12 & 48 & 72 & 24 & N/A & 1,800 & 3,204 \\
\hline Household average $^{5}$ & 2,621 & 15 & 94 & 162 & 25 & 36 & 6,241 & 9,195 \\
\hline - Large urban & 1,866 & - & 130 & 215 & 23 & 39 & 7,270 & 9,542 \\
\hline - Medium urban & 2,533 & 54 & 72 & 247 & 36 & 59 & 5,858 & 8,859 \\
\hline - Small urban & 3,482 & 18 & 77 & 75 & 10 & 7 & 6,676 & 10,346 \\
\hline - Rural & 3,388 & 3 & 70 & 52 & 25 & 25 & 4,848 & 8,410 \\
\hline South East average $^{6}$ & 3,120 & 30 & 120 & 180 & 60 & $N / A$ & 4,500 & 8,010 \\
\hline
\end{tabular}

Notes: ${ }^{(1)}$ Values from method A. Car emissions allocated to drivers. ${ }^{(2)}$ Includes local bus, express coach and community/minibus. ${ }^{(3)}$ Values from method E. Employs central $A I M$ value of 3 for flights above 30,000 ft altitude. ${ }^{(4)}$ Individual averages from all households. ${ }^{(5)}$ Household averages from complete households only. ${ }^{(6)}$ Based on 2.5 persons per household for England's South East region. Note S.E. regional averages exclude lifecycle emissions. For air travel emissions, a central AIM value of 3 over the published figures was applied simply for the purpose of comparing these with this research.

Additional sources: ONS (2004); ONS (2005a); ONS (2005b); DfT (2005)

Although the headline results presented above seem rather high, they largely confirm data obtained from national statistics (DfT, 2006a; ONS, 2004) and results of other work (e.g., Hillman and Fawcett, 2004). Any differences in results - mainly with regards to air travel can be explained by a combination of differences in accounting methods, emissions data sources and methods, local vs. regional variations, and better than average access by car and public transport to major international airports. Crucially, this research accounts for both directions of a return flight and further includes a distance penalty for detours from a theoretical 'as-the-crow-flies' route, taxiing and a cargo factor that reduces passengers' share of emissions by about $2 \%$. The sample also features a higher share of younger residents living in Oxford, e.g. a higher share of 19-35 old overseas students who tend to fly significantly more than the average person, as demonstrated later.

While keeping all other explanatory variables constant, geographical location of the household had a significant influence on GHG emissions levels. First, average emissions from residents living in large urban areas (basically Oxford City) were 16\% higher than the sample average, whereas emissions were lower (between $-10 \%$ and $-18 \%$ ) for other areas. In particular, emissions from air, bus/coach, rail and taxi travel were disproportionally higher for residents in large urban areas than the sample average, while conversely they were responsible for $26 \%$ lower emissions from car travel. This can be explained by a combination of good accessibility to public transport and airports as well as the effects of local transport policy, which largely 
restricts access to the city centre for private car (but not taxi) travel. Interestingly, residents in rural areas are responsible for $41 \%$ higher than average emissions from car but $29 \%$ lower than average emissions from air travel.

Secondly, the $3.5 \%$ share of the total from land-based public transport (bus, coach, minibus, rail and taxi) suggests that these modes can be considered insignificant overall. Although demonstrating the highest GHG emissions rates per passenger-km (Table 1), average emissions from travel by ferry are below $1 \%$.

Respondents were further ranked (smallest first, i.e. rank 1 for lowest emitter) according to GHG emissions levels. For emissions from all travel, Figure 2 shows an unequal distribution between individuals. This suggests that a large proportion of the population is responsible for similar $\mathrm{CO}_{2}$ emissions levels, whilst a few are responsible for a disproportionately large share of the total.

Figure 2: Individual GHG emissions from all travel activity by area type, ranked by emissions totals

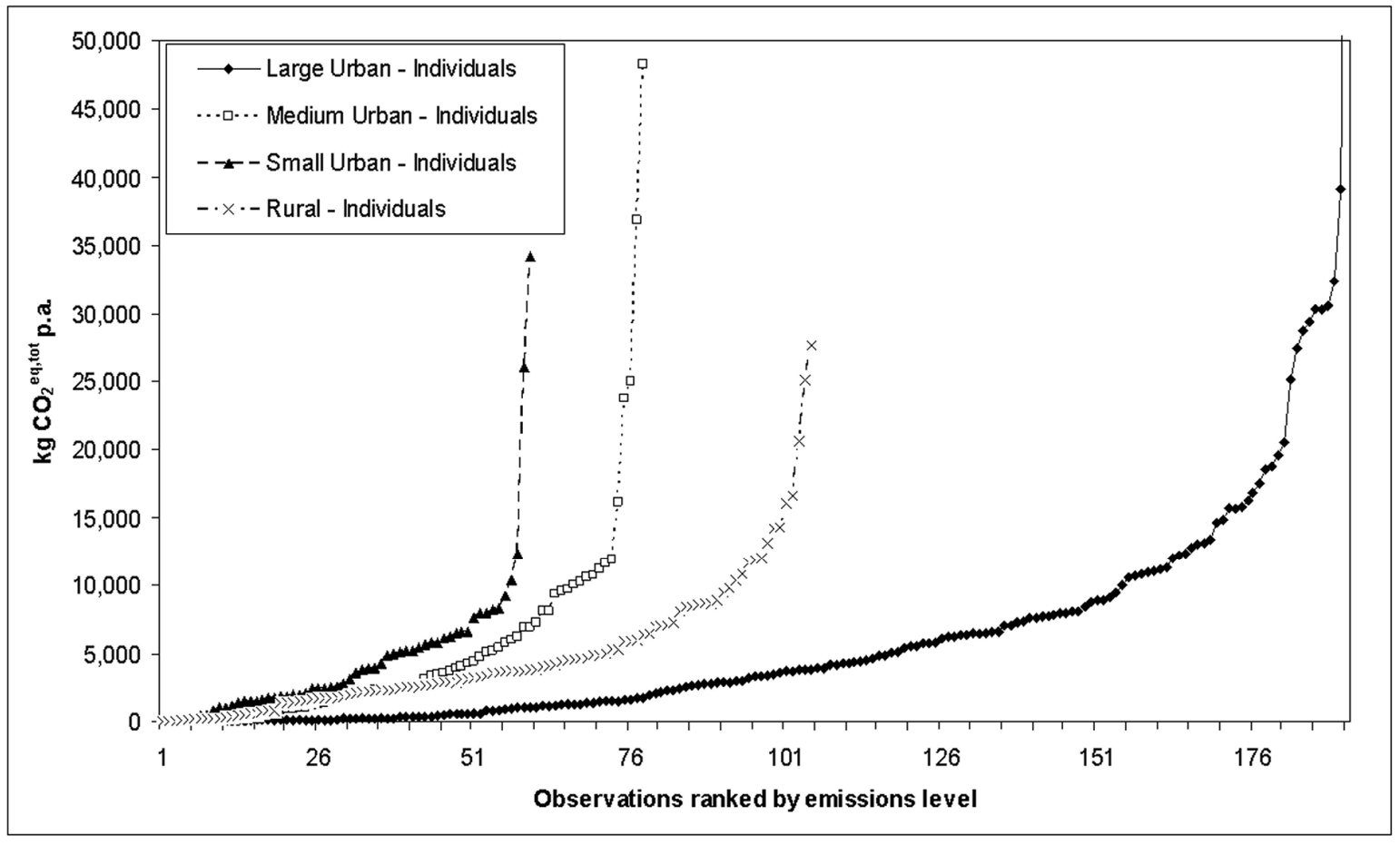

Base: 434 respondents who produced any emissions at all (i.e. 22 excluding non-travellers).

Note: an outlier of a respondent in large urban areas ( $>90,000 \mathrm{tCO}_{2}{ }^{\text {eq.tot }}$ p.a.) is not shown.

Further analysis using GIS mapping of GHG emissions can illustrate the relationship between emissions levels and geographical location of the household, thus visualising where the highest and lowest emitters lived and what the modal make-up was for each individual. As an example of this mapping exercise, Figure 3 shows a raster map of the City of Oxford, overlaid with pie charts of average GHG emissions per person for all travel. Higher total emissions are represented by larger pie chart sizes (on a square root scale rather than linear). Concentric pie 
charts show multiple respondents from the same household. The map visualises what was found in the quantitative analysis: GHG emissions from individuals living in large urban areas are dominated by air (cyan) and car (red). There are, however, some notable exceptions of rail (yellow) and bus (blue) users, all living in areas of good public transport accessibility. The map also indicates some unexpected cases or residuals/outlier. For example, a respondent from the South East of the City produced emissions totals of $89 \mathrm{tCO}_{2}{ }^{\text {eq,tot }}$ p.a., mainly from air travel (cyan) but also bus (blue). The regression analyses further below will confirm that this individual is indeed an 'outlier' ( $>3$ standard deviations away from mean), travelling many times more and further than the average by air. A map can only give a glance at the sample while further analysis of personal characteristics of the outliers is needed to provide further insights into how socio-economic factors influences total impact and modal contributions.

Figure 3: Mapping of household location and individual GHG emissions from all travel, represented by emissions levels (pie chart size) and modal shares (pie chart slices)

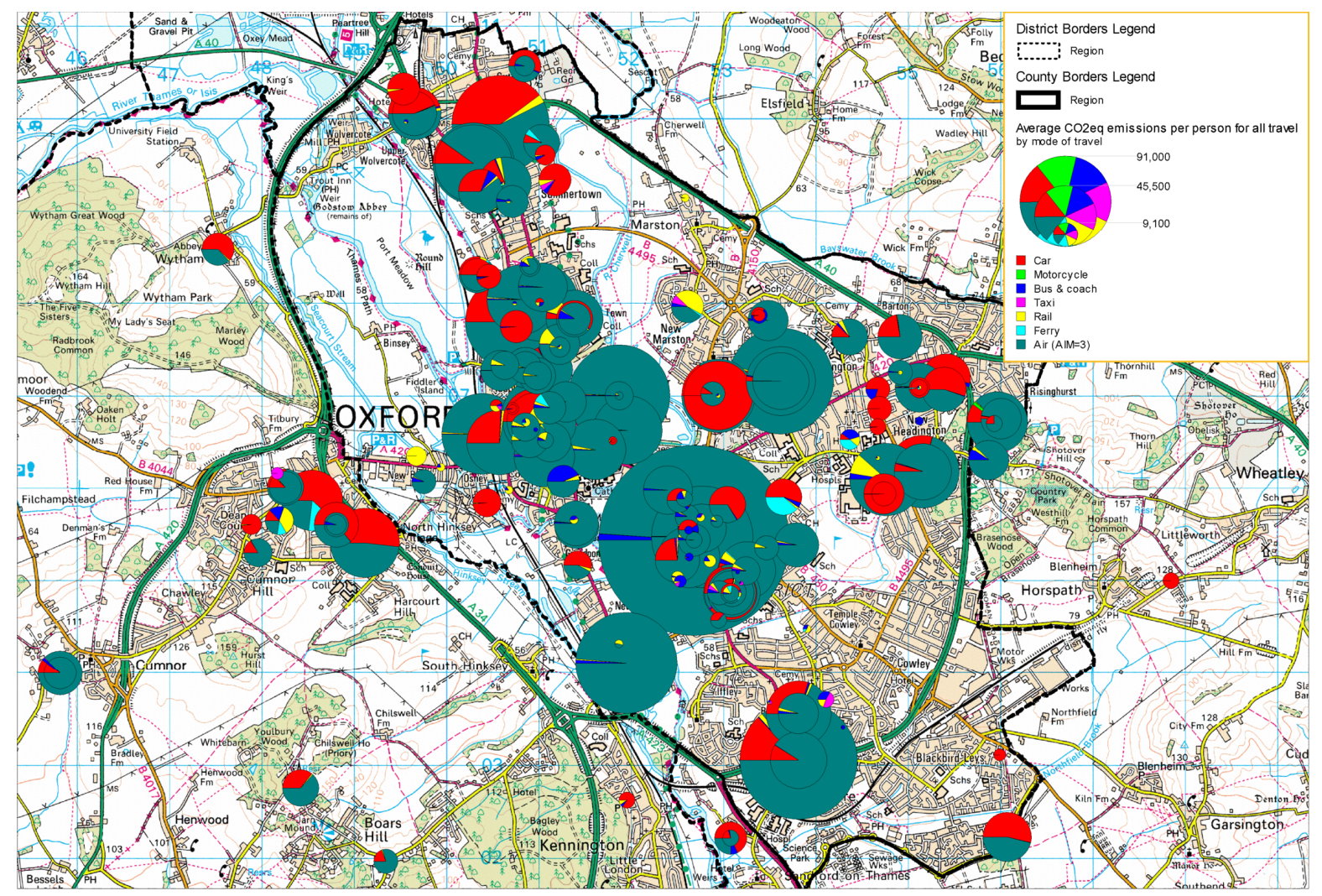

Sources: Household geographical information obtained from Postal Address File. Raster maps obtained under license from Ordnance Survey via EDINA (2006). Emissions derived in this research.

\subsection{Are there associations between travel emissions and personal characteristics?}

In addition to the continuous distribution of emissions, the results were reduced so as to rank each individual or household according to where they lie in a scale of 'high' or 'low' polluters across the transport modes. Respondents were ranked and grouped into emissions quintiles 
and deciles, that is, into groups of a fifth and a tenth of the total case base each based on their emissions levels.

Overall, GHG emissions appear to be unequally distributed amongst the population. It is a minority of users, travelling comparatively long distances, who account for the differences between high and low quintiles. $61 \%$ of emissions were produced from respondents in the highest emissions quintile, but only less than $1 \%$ of emissions were generated from respondents in the lowest quintile, implying a 'high-over-low' factor of 90. Similarly, the top emissions decile of the sample are responsible for $43 \%$ and the bottom emissions decile of the respondents only $0.1 \%$ of the total $\mathrm{CO}_{2}{ }^{\text {eq,tot }}$. Respondents in the top emissions decile were typically in their $30 \mathrm{~s}$ and $40 \mathrm{~s}$, in full-time work or at university and earning $£ 30 \mathrm{k}$ or more. Almost all of the respondents in the top emissions decile flew regularly, undertaking on average 12.7 LTOs and flying 53,861 km per year. In terms of total distance travelled, this is more than 5 times the sample average (10,249 km p.a.) and, astoundingly, 30\% more than the circumference of the earth. Furthermore, $72 \%$ of the respondents in the top emissions decile drove a car an average of 13,570 driver-km per year (or $37 \mathrm{~km}$ a day) - i.e. two-and-a-half times the UK national average of 5,582 $\mathrm{km}$ (ONS, 2005b).

In order to test for any associations between emissions and personal characteristics, a series of cross tabulations and chi-square tests was undertaken. This analysis suggests that GHG emissions levels are associated with (a) income levels, (b) working status, (c) gender and travel by private vehicles, (d) age, (e) household composition and size, (f) car availability and (g) car ownership (private vs. company car). For instance, more than a quarter of the respondents in the highest emissions quintile were in the highest income group, while about three-quarters of the respondents in the lowest emissions quintile were in the lowest income group (Figure 3). Respondents in the highest income group produced on average 3.5 times the annual emissions level of respondents in lowest income group. This disproportionality was significant (chi square test, $p<0.05$ ) for 'all travel' as well as travel by car, rail and taxi. This compares well with national statistics. In 2006, people in the highest income quintile did nearly $30 \%$ more trips than those in the lowest income quintile and travelled nearly three times further (ONS, 2007). Secondly with regard to working status, about three-quarters of those in the top emission quintile were in work, whilst about four-fifths of those in the lowest emissions quintile were not. The relationship was highly significant $(p<0.01)$ for emissions from 'all travel', car and rail. Emissions from rail travel provide the strongest of these links, likely to be rooted in good accessibility to rail services for many respondents and the relatively high share of regular rail users (commuters). As with income, air travel emissions showed only weak links to working status. Thirdly, age was associated with emissions levels. Two-thirds of respondents in the highest emissions quintile (all travel) were between 36 and 65 year old, while two-fifths of respondents in the lowest emissions quintile were 66 years or older. The association between age and emissions levels was highly significant $(p<0.01)$ for 'all travel', car, rail and, crucially, air travel.

[Figure 4] 
Figure 4: Composition of survey responses by emissions quintile and income group (all travel)

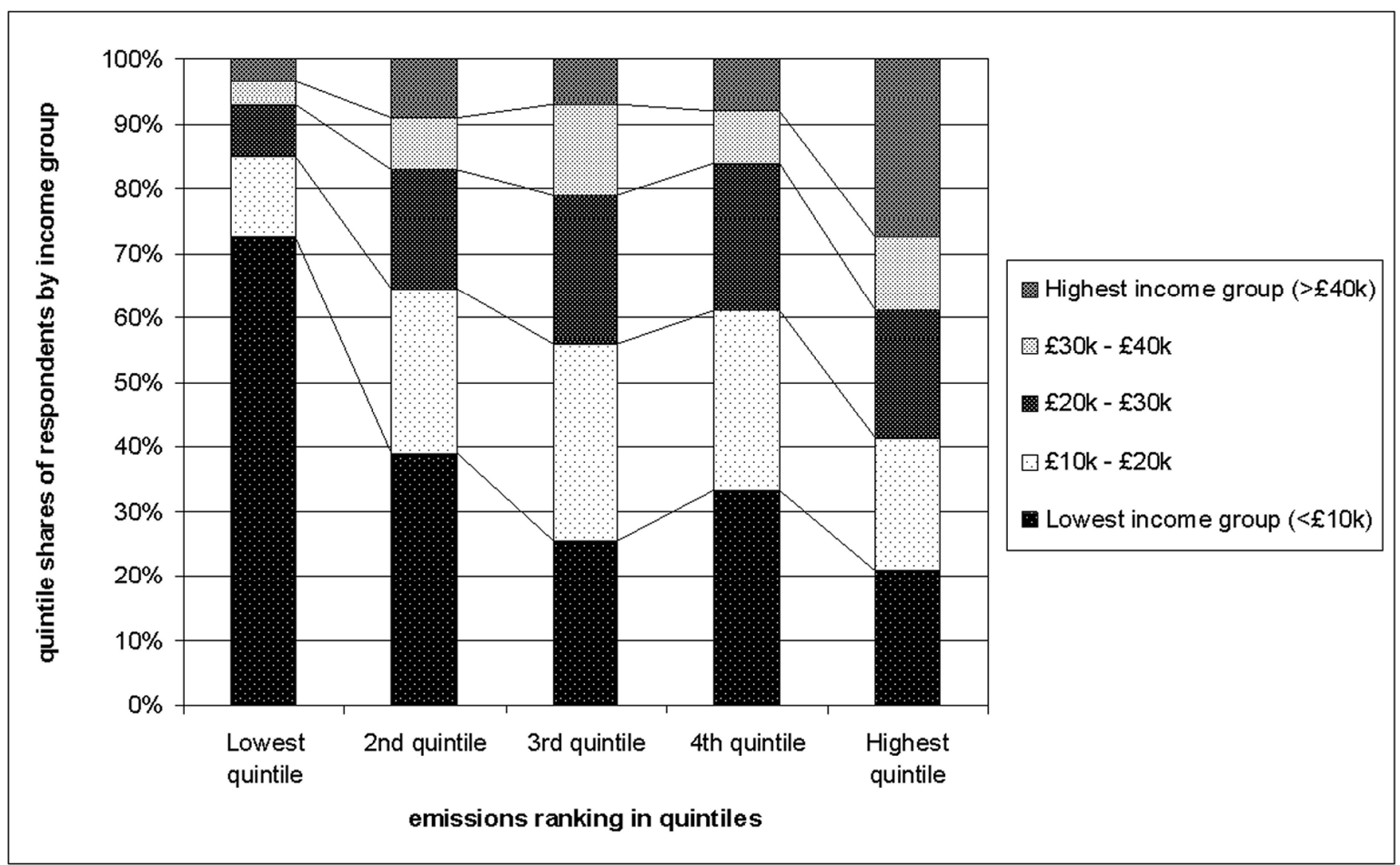

Base: 434 respondents who produced any emissions at all and provided information on income.

Car availability showed strong relationship with emissions. Overall, households with access to two cars or more produced about $75 \%$ higher emissions levels per household than the sample average and more than twice the figure for households owning only one car. Similarly, emissions from car travel were highest from households with access to two cars or more at about twice the sample average. Finally, car ownership (company car vs. private car) related to emissions levels. For personal usage, company cars were driven about $50 \%$ further than private cars, with even higher distances travelled on business in company cars. As found in other research (e.g. Hughes, 1994; ONS, 2005b), the company cars in this sample were significantly younger and larger (in terms of engine size) than the average car fleet.

\subsection{What are the significant factors underlying emissions levels, and how strong is the relationship?}

Clearly the above analysis can only show associations, partly because of the limitations of cross tabulation and chi-square significance tests, but also because it focuses on univariate analyses that may hide major correlations between, say, income and working status or income and age. Thus multivariate regression analyses were performed involving a considerable number of multiple linear regressions of annual mileage or emissions (dependent variables) as a function of gender, income, working status, age, car availability and other factors (independent variables). This also included a number of the accessibility variables (access as 
measured in time to employment, shopping centres, supermarkets, railway station or the local bus stop) that were surveyed but have not been discussed in this paper thus far. The methods used follow standard econometric literature (Kennedy, 2003). The main dependent variable of this analysis was $\mathrm{CO}_{2}{ }^{\text {eq,tot }}$ from 'all travel'. Other dependent variables investigated were $\mathrm{CO}_{2}{ }^{\text {eq,tot }}$ for car, air, bus \& coach and rail travel. Given the shapes of the emissions ranking curves, the dependent variables were log-transformed by calculating the normal log of the emissions values.

Twelve independent variables were defined, with between two and seven categorical or ordinal variables each. The number of independent variables and cases (456 overall, 269 for air, 266 for car) satisfy the common rule of thumb that for good results there should be a minimum of 20 times more cases than independent variables (David and Sutton, 2004; Kennedy, 2003). As the independent variables were available as qualitative, discrete categorical/ordinal values (e.g. discrete income bands, gender, working status), they were dummy coded in the standard binary method of being equal to 1 (present) or 0 (not present). Each value of a categorical/ordinal variable except one was entered as a dichotomy (e.g., 'Male' $=1$ if respondent is male, otherwise 0; 'Worker' $=1$ if respondent is in work, otherwise 0 ; etc.). The independent variables and their categorical and ordinal variables are shown in Table 2.

Table 2: Independent variables and their categorical and ordinal variables, multivariate regression model

\begin{tabular}{|c|c|c|c|c|c|c|c|c|}
\hline Independent & \multicolumn{8}{|c|}{ Categorical and ordinal variables } \\
\hline Gender & \multicolumn{4}{|l|}{ Male } & \multicolumn{4}{|l|}{ Female } \\
\hline Age & Less19yrs & \multicolumn{2}{|c|}{19 to25yrs } & 26to35yrs & 36to50yrs & 50 to65yrs & 66to75yrs & More76yrs \\
\hline Working status & $\begin{array}{l}\text { WorkFT } \\
\text { (full time } \\
\text { work) }\end{array}$ & \multicolumn{2}{|c|}{$\begin{array}{l}\text { WorkPT } \\
\text { (part time } \\
\text { work) }\end{array}$} & $\begin{array}{l}\text { KeepHouse } \\
\text { (keeping } \\
\text { house/ } \\
\text { carer) } \\
\end{array}$ & $\begin{array}{l}\text { Univ_FE (at } \\
\text { university } \\
\text { or in further } \\
\text { education) }\end{array}$ & $\begin{array}{l}\text { Unemploye } \\
\text { d }\end{array}$ & $\begin{array}{l}\text { School } \\
\text { (students at } \\
\text { school) }\end{array}$ & $\begin{array}{l}\text { Retired } \\
\text { (retired or } \\
\text { pensioner) }\end{array}$ \\
\hline Income & \multicolumn{2}{|c|}{ LowInc $(<£ 10 \mathrm{k})$} & \multicolumn{2}{|c|}{$£ 10 \_20 \mathrm{k}$} & \multicolumn{2}{|l|}{$£ 20 \_30 \mathrm{k}$} & $£ 30 \_40 \mathrm{k}$ & $\begin{array}{l}\text { HighInc } \\
(>£ 40 \mathrm{k})\end{array}$ \\
\hline Car availability & \multicolumn{2}{|l|}{ NoCar } & \multicolumn{2}{|c|}{ OneCar } & \multicolumn{2}{|c|}{ TwoOrMoreCars } & & \\
\hline $\begin{array}{l}\text { Household } \\
\text { location }\end{array}$ & \multicolumn{2}{|c|}{$\begin{array}{l}\text { LUrban (large } \\
\text { urban) }\end{array}$} & \multicolumn{2}{|c|}{$\begin{array}{l}\text { MUrban (medium } \\
\text { urban) }\end{array}$} & \multicolumn{2}{|c|}{ SUrban (small urban) } & Rural & \\
\hline $\begin{array}{l}\text { Accessibility to } \\
\text { employment }\end{array}$ & \multicolumn{4}{|c|}{ AWorkGood (access time $\leq 20 \mathrm{~min}$ ) } & \multicolumn{4}{|c|}{ AWorkPoor (access time $>20 \mathrm{~min})$} \\
\hline $\begin{array}{l}\text { Accessibility to } \\
\text { (large) } \\
\text { supermarkets }\end{array}$ & \multicolumn{4}{|c|}{ ASuperMaGood (access time $\leq 20 \mathrm{~min})$} & \multicolumn{4}{|c|}{ ASuperMaPoor (access time $>20 \mathrm{~min}$ ) } \\
\hline $\begin{array}{l}\text { Accessibility to } \\
\text { shopping and } \\
\text { commercial } \\
\text { centres }\end{array}$ & \multicolumn{4}{|c|}{ AStoresGood (access time $\leq 20 \mathrm{~min}$ ) } & \multicolumn{4}{|c|}{ AStoresPoor (access time $>20 \mathrm{~min}$ ) } \\
\hline $\begin{array}{l}\text { Accessibility to } \\
\text { sport and leisure }\end{array}$ & \multicolumn{4}{|c|}{ ALeisureGood (access time $\leq 20 \mathrm{~min}$ ) } & \multicolumn{4}{|c|}{ ALeisurePoor (access time $>20 \mathrm{~min}$ ) } \\
\hline $\begin{array}{l}\text { Accessibility to } \\
\text { railway station }\end{array}$ & \multicolumn{4}{|c|}{ AStaGood (access time $\leq 10 \mathrm{~min})$} & \multicolumn{4}{|c|}{ AStaPoor (access time >10min) } \\
\hline $\begin{array}{l}\text { Accessibility to } \\
\text { local bus stop }\end{array}$ & \multicolumn{4}{|c|}{$\begin{array}{l}\text { ABusGood (access time } \leq 10 \mathrm{~min} \text { AND } \\
\text { weekday frequency } \geq 6 \text { per hour) }\end{array}$} & \multicolumn{4}{|c|}{$\begin{array}{l}\text { ABusPoor (access time }>10 \text { min OR weekday frequency } \leq \\
6 \text { per hour) }\end{array}$} \\
\hline
\end{tabular}


In each variable group, one categorical value was left out to prevent perfect multicollinearity in the model. This left-out value represents the reference value that the other categorical values are compared with. As a result of this dummy coding, the maximum number of categorical variables was 28 . The regression model thus takes the general form:

$$
\begin{aligned}
& \ln \left(C_{2}^{\text {eq,tot }}\right)=C+B_{1} \times \text { Male }+B_{2} \times \text { Less } 19 \text { yrs }+B_{3} \times 19 \text { to } 25 \text { yrs }+B_{4} \times 26 \text { to } 35 \text { yrs } \\
& +B_{5} \times 51 \text { to } 65 \text { yrs }+B_{6} \times 66 \text { to } 75 \text { yrs }+B_{7} \times \text { More } 75 \text { yrs }+B_{8} \times \text { WorkPT } \\
& +B_{9} \times \text { Univ } \_F E+B_{10} \times \text { Re tired }+B_{11} \times \text { KeepHouse }+B_{12} \times \text { School } \\
& +B_{13} \times \text { Unemployed }+B_{14} \times \text { LowInc }+B_{15} \times £ 20_{-} 30 k+B_{16} \times £ 30 \_40 k \\
& +B_{17} \times \text { HighInc }+B_{18} \times \text { NoCar }+B_{19} \times \text { TwoOrMoreCars }+B_{20} \times \text { MUrban } \\
& +B_{21} \times \text { SUrban }+B_{22} \times \text { Rural }+B_{23} \times \text { AWorkGood }+B_{24} \times \text { ASuperMaGood } \\
& +B_{25} \times \text { AStoresGood }+B_{26} \times \text { ALeisureGood }+B_{27} \times \text { AStaGood }+B_{28} \times \text { ABusGood }
\end{aligned}
$$

where $\mathrm{CO}_{2}{ }^{\text {eq,tot }}$ is the dependent variable, $C$ is the constant or intercept and the $B_{n}$ 's are the regression coefficients for the corresponding categorical variables.

As a first step, all variables were entered into equation E3 regardless of their suspected significance or multicollinearity. This model was significant $(p<0.001)$ and explained $37 \%$ of the variation in emissions (Table 3 ). However, only 7 coefficients were significant $(p<0.05)$, and there were minor collinearity problems.

The significant variables were pensionable age ('66to75yrs', Beta $6=-0.312$; 'More75yrs', Beta $7=-0.256)$, no access to a car ( 'NoCar', Beta $18=-0.277)$, at university of in full time education ('Univ_FE', Beta $9=+0.181$ ), at school ('School', Beta $12=-0.169$ ), house keeper or carer ('KeepHouse', Beta $\left.{ }_{11}=-0.160\right)$ and low income ('LowInc', Beta ${ }_{14}=-0.148$ ). High income ('HighInc', Beta $17=+0.102$ ) was just above the $5 \%$ significance level. The signs of the coefficients are as expected: older people travel less by car and air; no access to a car means no emissions from car travel; (overseas) students in higher education make more use of the opportunity to travel further while keeping a house usually means the opposite; and being on low income of less than $£ 10 \mathrm{k}$ a year seems to curb carbon intensive travel. The key message here is though that the majority of variables did not contribute significantly and explain the variation in emissions. Importantly, overall emissions were not influenced significantly by gender, household location and accessibility over and above the variation explained by the 7 significant categorical variables. In terms of collinearity, five tolerance figures were below 0.5, while equally five VIF (variance inflation factor) figures were above 2.0, suspecting serious multicollinearity problems with this model. However, further collinearity diagnostics showed that the condition indices of the 26 variables were all under 15 , suggesting the collinearity problem was weak rather than serious. 
Table 3: Regression model results for the natural log of greenhouse gas emissions $\left(\mathrm{CO}_{2}{ }^{\text {eq,tot }}\right)$ from all individual travel

\begin{tabular}{|c|c|c|c|c|c|c|c|}
\hline \multicolumn{8}{|c|}{ Summary and ANOVA } \\
\hline $\mathrm{N}$ & \multicolumn{2}{|c|}{434} & \multicolumn{4}{|c|}{ Mean of dependent var. $\ln \left(\mathrm{CO}_{2}^{\text {eq,tot }}\right)$} & 8.56 \\
\hline $\mathrm{R}^{2}$ & \multicolumn{2}{|c|}{0.371} & \multicolumn{4}{|c|}{ Standard error of the estimate } & 1.501 \\
\hline Adjusted $\mathrm{R}^{2}$ & \multicolumn{2}{|c|}{0.330} & \multicolumn{4}{|l|}{ df } & 26 \\
\hline $\mathrm{F}$ & \multicolumn{2}{|l|}{9.215} & \multicolumn{4}{|c|}{ Significance of F } & $<0.001$ \\
\hline \multicolumn{8}{|c|}{ Coefficients } \\
\hline & \multicolumn{2}{|c|}{ Unstd. coeff. } & \multirow{2}{*}{$\begin{array}{l}\begin{array}{l}\text { Std. } \\
\text { coeff. }\end{array} \\
\text { Beta }_{n}\end{array}$} & \multirow[t]{2}{*}{$\mathrm{T}$} & \multirow[t]{2}{*}{ Sig. } & \multicolumn{2}{|c|}{ Collinearity } \\
\hline & $\mathrm{B}_{\mathrm{n}}$ & $\begin{array}{l}\text { Std. } \\
\text { error }\end{array}$ & & & & Tol. & VIF \\
\hline C (Constant) & 7.892 & .347 & & 22.733 & .000 & & \\
\hline Male & .252 & .157 & .069 & 1.603 & .110 & .844 & 1.185 \\
\hline 19to25yrs & .017 & .311 & .003 & .056 & .956 & .517 & 1.934 \\
\hline 26to35yrs & .055 & .252 & .012 & .220 & .826 & .545 & 1.834 \\
\hline 51to65yrs & -.277 & .237 & -.060 & -1.172 & .242 & .583 & 1.716 \\
\hline 66to75yrs & -1.632 & .357 & -.312 & -4.569 & .000 & .332 & 3.011 \\
\hline More75yrs & -1.793 & .431 & -.256 & -4.157 & .000 & .409 & 2.448 \\
\hline KeepHouse & -1.396 & .432 & -.160 & -3.232 & .001 & .632 & 1.581 \\
\hline Retired & .453 & .372 & .103 & 1.219 & .223 & .218 & 4.593 \\
\hline Unemployed & -.484 & .936 & -.022 & -.516 & .606 & .862 & 1.160 \\
\hline School & -1.261 & .415 & -.169 & -3.042 & .003 & .500 & 1.999 \\
\hline Univ_FE & .935 & .297 & .181 & 3.150 & .002 & .469 & 2.133 \\
\hline WorkPT & .533 & .287 & .091 & 1.860 & .064 & .642 & 1.559 \\
\hline$£ 20 \_30 \mathrm{k}$ & .274 & .247 & .058 & 1.108 & .269 & .563 & 1.775 \\
\hline$£ 30 \_40 \mathrm{k}$ & .442 & .317 & .069 & 1.393 & .164 & .630 & 1.588 \\
\hline LowInc & -.557 & .224 & -.148 & -2.492 & .013 & .439 & 2.278 \\
\hline HighInc & .599 & .311 & .102 & 1.927 & .055 & .547 & 1.829 \\
\hline NoCar & -1.181 & .216 & -.277 & -5.461 & .000 & .602 & 1.662 \\
\hline TwoCarsOrMore & .133 & .191 & .034 & .698 & .486 & .639 & 1.565 \\
\hline MUrban & -.182 & .235 & -.038 & -.778 & .437 & .639 & 1.565 \\
\hline SUrban & .326 & .262 & .061 & 1.246 & .213 & .636 & 1.572 \\
\hline Rural & .205 & .226 & .048 & .909 & .364 & .555 & 1.802 \\
\hline ASuperMaGood & .209 & .214 & .047 & .976 & .330 & .675 & 1.482 \\
\hline AStoresGood & -.017 & .214 & -.004 & -.078 & .938 & .522 & 1.916 \\
\hline ALeisureGood & -.248 & .191 & -.068 & -1.298 & .195 & .571 & 1.752 \\
\hline AStaGood & .085 & .230 & .017 & .372 & .710 & .773 & 1.293 \\
\hline ABusGood & .191 & .172 & .050 & 1.111 & .267 & .761 & 1.314 \\
\hline
\end{tabular}

Notes: Significant $(p<0.05)$ variables in bold. The categorical variable 'Less 19yrs' was excluded due to zero tolerance in terms of collinearity with variable 'School' $\mathrm{N}=$ number of valid cases. $\mathrm{F}=\mathrm{F}$ test. $\mathrm{df}=$ degrees of freedom. Sig. = significance. Tol. $=$ tolerance. $\mathrm{VIF}=$ variance inflation factor. $B_{n} /$ Beta $_{n}=$ coefficients (equation E3). 
As for the outliers, the most 'worrisome' case was an Oxford City respondent between 36 and 50 years of age and income of $£ 50 \mathrm{k}$ p.a. or more, travelling a disproportionally high amount by air ( 238 thousand $\mathrm{km}$ ) and coach (19 thousand $\mathrm{km}$, likely to come from day-to-day commuting to London), and thus producing the highest total in the sample of $90 \mathrm{tCO}_{2}{ }^{\text {eq,tot }}$.

As a second step, the general model was reduced to a number of alternative regression models in order to test a number of hypotheses motivated by the cross-tabulation analysis above. How strong is the association between emissions from all travel and income and/or working status? How strong is it between air travel emissions and income, age and/or household location? Between car travel emissions and gender and/or car ownership? Between public transport travel emissions and car ownership, income, age, household location and or accessibility to bus or rail stations?

The models testing these hypotheses used the stepwise approach of entering (or removing) a variable into equation $\mathrm{E} 3$, depending on whether the additional variable improved the model-to-data fit or not. The stepwise approach removed any multicollinearity problems.

While the full analysis (detailed in Brand, 2008) goes beyond the scope of this paper, a number of results are worth highlighting. Distance travelled by car and GHG emissions from car travel (for the 269 drivers only) were both significantly related to pensionable age (negative influence), high car ownership (positive influence) and 'being male' (positive influence). Interestingly, income, household location, accessibility and working status did not add significant terms to the car (driver) model. Furthermore, emissions from air travel (269 fliers only) were positively influenced by higher income ('HighInc', Beta=+0.159), while pensionable age ('66to75yrs', Beta=-0.259; 'More75yrs', Beta=-0.131), household location in rural and medium urban areas ('Rural', Beta=-0.192; 'MUrban', Beta=-0.123) and being a house keeper or carer ('KeepHouse', Beta=-0.108) had negative influence. As for public transport, the bus travel emissions model suggests a positive influence on emissions for respondents who did not have access to a car. Conversely, the strongest negative influences were observed for respondents with access to two or more cars and living in medium urban areas with good accessibility to bus services. Moreover, the rail emissions regression showed that higher incomes, the absence of a car, being between 19 and 25 years of age and good accessibility to the nearest railway station are associated with higher rail (use and) emissions. Conversely, children and respondents of 76 years or older show a 'negative' effect on emissions.

\section{ISSUES AND IMPLICATIONS}

\subsection{Validation and methodological issues}

One concern of the adopted approach is the potential lack of recollection of travel activity over a 12 month period. This was addressed in a number of ways. First, the collected data were checked in terms of internal consistency and integrity by employing triangulation, i.e. a number of alternative methods (records of annual distance travelled vs. estimates of fuel consumption) to get to the same output (emissions). Secondly, the bottom-up data were 
weighted to allow for non-response effect as outlined in Stopher (2000), aggregated and compared at higher levels of analysis. This showed a good match with national and regional statistics for car, air and bus travel (see Brand and Boardman, 2008 for more details). Any differences for modes could be explained by differences in data collection methods, coverage and analysis.

Whilst the validation procedures have been unable to assess conclusively the accuracy of the data in so far as it is a true reflection of individual emissions from travel activity, the following conclusions can be drawn. The use of any documented evidence to record distance travelled (such as the MoT certificates requested for all household cars), and any other pieces of information requested, produces considerably better results. Also, by asking respondents how accurate their estimates of the distance travelled by car or motorcycle are, an assessment of confidence levels was obtained, thus keeping uncertainty to a minimum.

The mixed-method approach used for car and air travel provided further insights. First, methods 'A' (based on travel activity and disaggregate emissions factors) and 'B' (based on 'official' vehicle-specific fuel consumption and emissions figures) for car travel produced remarkably similar results overall. However, emissions varied considerably on a case by case basis, revealing how different approaches can lead to different results at the disaggregate level. Given the uncertainty in individual emissions totals, however, both methods produce largely similar results. The travel emissions method (A), however, is more disaggregate and leaves room for patterns to emerge relating to disproportionate usage of different road types and trip lengths.

For air travel, overall distance and duration estimates between the two tested methods ' $E$ ' (distance based, based on origin and destination airports) and ' $F$ ' (based on stated duration) can, at least at the sample level, be used interchangeably as the key parameters determining emissions from air travel. The scientific uncertainty surrounding non- $\mathrm{CO}_{2}$ effects is treated by using a range of values for the Aviation Impacts Multiplier.

Finally, an attempt was made to assess any uncertainty in the final outputs, including uncertainty in survey input variables provided by respondents (e.g. annual car mileage, flight duration, day-to-day public transport mileages); uncertainty in published and assumed input variables (e.g. Aviation Impacts Multiplier, emissions factors and occupancy rates); and statistical errors (overall sample error based on Gaussian error propagation for downstream variables, taking care of distinguishing between independent and dependent variables). At the individual level, uncertainty in the final results was considerable, as uncertainty increases at each step in the calculations, depending on the uncertainty factors for each parameter used. For instance, the individual uncertainty of $\mathrm{CO}_{2}$ emissions from car travel was derived at between $\pm 14 \%$ and $\pm 30 \%$, depending on whether MoT records, registration document and current meter reading or personal estimates were used. Similarly, an uncertainty of $\pm 29 \%$ was derived for individual $\mathrm{CO}_{2}{ }^{\text {eq,tot }}$ emissions from air travel (mainly due to uncertainty in actual occupancy rates). At the sample level, on the other hand, this uncertainty averages out, as respondents can be considered independent of each other. Taking the same examples from above, the sample uncertainty of $\mathrm{CO}_{2}{ }^{\text {eq,tot }}$ emissions from car and air travel was derived as 
below $\pm 1.5 \%$, while the sample uncertainty for public transport was slightly higher at $\pm 4 \%$ (rail, bus).

\subsection{Insights for policy}

The unequal distribution of GHG emissions - by and large following a 60-20 rule i.e. $60 \%$ of emissions are produced by $20 \%$ of the population - is significant for the realisation that policy intervention must be particularly aimed at a minority of the population in order to be effective. Almost all of the respondents in the highest emissions decile flew or drove long distances, flying more than five times and driving more than twice the sample average. Policy needs to target these high emitters by seeking out differences amongst the population, identify the causes and target these causes directly. Arguably the two main challenges are: (a) how to identify and then target high users (as there is such a range and spread of travel activity and associated emissions) and (b) how to deal with the concentration of emissions among a relatively small share of the population yet not hurt the poor who emit very little because they are poor. Carbon pricing (e.g. a downstream carbon tax) and downstream cap-and-trading (e.g. domestic tradable quotas or personal carbon allowances) are two of the main policy approaches to tackle carbon emissions. Both approaches target high users directly while the debate about which approach has fewer distributional impacts continues. For example, research by Ekins and Dresner (2004) and Dresner (2005) suggests that a carbon tax with revenues redistributed through benefits and tax credits could be more progressive (i.e. fewer people in the lowest income groups would be worse off) than downstream trading while KeayBright and Fawcett (2005) and Fawcett et al. (2007) highlight the latter's potential effectiveness, equity, distributional impacts and certainty, in principle, of delivering savings.

Crucially, this research suggests that flying has to be included in either approach, as a carbon tax on fuel (upstream tax), air passenger charge (downstream tax), emissions trading (upstream) or personal carbon trading (downstream). However, aviation is problematic as solutions to tackle climate change have to be international. The aviation sector is currently excluded from both fuel taxation, value added tax and emissions trading (although it will join the EU Emissions Trading Scheme as of 2012), suggesting something must be done sooner rather than later to curb the rising demand. Higher air travel costs may prevent people from forming 'frequent flier' habits before they are 'engrained' in society. In the meantime, prices would have to go up considerably to have a restraining effect on demand, mainly because the link between prices and flying is evidently weak (Brons et al., 2002).

Household location is associated with emissions levels when socio-economic, lifestyle or other factors are not accounted for, confirming results in other studies (e.g. Cameron et al., 2003; Carlsson-Kanyama and Linden, 1999; Susilo and Stead, 2007). Residents in large urban areas may experience more difficulties in meeting any future caps on personal GHG emissions (e.g. as part of carbon cap-and-trading) - yet alternatives to the car are generally available, so the scale of any equity impacts will be lower. However, regular flying will most certainly pose a challenge to meeting carbon caps which by 2050 could be in the order of $1 \mathrm{tCO}_{2}^{\text {eq,tot }}$ per 
person per year (Hillman and Fawcett, 2004). This level of GHG emissions is reached by a single return flight from the UK to Southern Europe (e.g. Malaga, Athens).

\section{CONCLUSIONS}

This paper contributes to the literature primarily by providing insights into cross-modal travel emissions profiling at the personal and household levels in a number of geographical settings. The regression analyses showed that there are significant relationships between outcomes (emissions, travel activity) and predictors (socio-economic and other factors). While some variables related to 'income' (low, high), 'age' (18 years or younger, 66 years or older), 'car availability and gender' (no car, two cars or more, being male - for car travel and emissions analysis only) and 'household location' (mainly for air and bus travel) were significant, others were not, most notably accessibility variables. However, none of the regression models explained the variation in outcomes of more than $38 \%$, and only a relatively small number of categorical independent variables were significant for each model. Thus, other factors such as attitudes, lifestyle and personal circumstances are likely to play an important role in explaining the other variations. This suggests that there may be a need for an alternative or complimentary segmentation of the personal travel market, for example by segmenting the population into potential 'mode switchers' via cluster analysis as performed by Anable (2005) for a sample of day travellers and currently investigated by the UK Department for Transport on a national scale (DfT, 2008a).

In terms of research needs and future work, the debate about carbon taxes vs. cap-andtrading as well as energy poverty issues would benefit from an extension to a profile of all personal carbon emissions by integrating GHG emissions from personal travel and domestic energy use. 


\section{REFERENCES}

AEA, 2002. Statistical Appendices to Yearbook 2002. Association of European Airlines, Brussels.

Anable, J., 2005. 'Complacent Car Addicts' or 'Aspiring Environmentalists'? Identifying travel behaviour segments using attitude theory. Transport Policy 12, 65-78.

Anable, J., Boardman, B., Root, A., 1997. Travel Emissions Profiles: a tool for strategy development and driver advice. Environmental Change Unit, University of Oxford, Oxford.

Banister, D., 1993. Energy use, transport and settlement patterns, in: Breheny, M. (Ed.), Sustainable Development and Urban Form. Pion, London, pp. 160-181.

Barlow, T.J., Hickman, A.J., Boulter, P., 2001. Exhaust Emission Factors 2001: Database and Emission Factors, TRL Report PR/SE/230/00. TRL, Crowthorne.

Best, H., Lanzendorf, M., 2005. Division of labour and gender differences in metropolitan car use: An empirical study in Cologne, Germany. Journal of Transport Geography 13, 109-121.

Brand, C., 2008. Personal Travel and Climate Change - Exploring Climate Change Emissions from Personal Travel Activity of Individuals and Households, 1st ed. Verlag Dr. Müller (VDM), Saarbrücken.

Brand, C., Boardman, B., 2008. Taming of the few - The unequal distribution of greenhouse gas emissions from personal travel in the UK. Energy Policy 36, 224-238.

Brand, C., Mattarelli, M., Moon, D., Calvo, R.W., 2002. STEEDS: A strategic transportenergy-environment decision support. European Journal of Operational Research 139, 416-435.

Brand, C., Preston, J., 2003. Which technology for urban public transport? Proceedings of the Institution of Civil Engineers - Transport.

Brög, W., Erl, E., Mense, N., 2004. Individualised Marketing: Changing Travel Behaviour for a better Environment, in: OECD (Ed.), Communicating Environmentally Sustainable Transport - The Role of Soft Measures. OECD, Paris, pp. 83-97.

Brons, M., Pels, E., Nijkamp, P., Rietveld, P., 2002. Price elasticities of demand for passenger air travel: a meta-analysis. Journal of Air Transport Management 8, 165-175.

CAA, 2005. Air Passenger Survey report 2005. Civil Aviation Authority, London.

CAA, 2006. January 2006 Airline Statistics. Civil Aviation Authority, TSO, London. 
Cairns, S., Newson, C., 2006. Predict and decide: aviation, climate change and policy. Environmental Change Institute, Oxford.

Cameron, I., Kenworthy, J.R., Lyons, T.J., 2003. Understanding and predicting private motorised urban mobility. Transp. Res.: Part D: Transport Environ. 8, 267-283.

Carlsson-Kanyama, A., Linden, A.-L., 1999. Travel patterns and environmental effects now and in the future:: implications of differences in energy consumption among socioeconomic groups. Ecol. Econ. 30, 405-417.

CfIT, 2001. A Comparative Study of the Environmental Effects of Rail and Short-haul Air Travel, Final Report. AEA Technology and Civil Aviation Authority for the Commission for Integrated Transport (CfIT), London.

David, M., Sutton, C.D., 2004. Social Research: The Basics. Sage Publications, London.

De Ceuster, G.E., Van Herbruggen, B., Logghe, S., Proost, S., 2004. The TREMOVE 2.0 Model Description. Transport \& Mobility Leuven and K.U. Leuven for the European Commission, DG ENV, Directorate C, Leuven and Brussels.

DEFRA, 2006. about: Climate Change, e-Digest of Statistics. Department for Environment, Food and Rural Affairs (DEFRA), TSO, London.

DfT, 2003. Car use in GB, Personal Travel Factsheet 7. Department for Transport (DfT), TSO, London.

DfT, 2005. Transport Statistics Great Britain: 2005 edition. Department for Transport (DFT), TSO, London.

DfT, 2006a. Climate change and transport. Department for Transport (DfT), TSO, London.

DfT, 2006b. Transport Statistics Great Britain: 2006 edition. Department for Transport (DFT), TSO, London.

DfT, 2008a. Social, Economics and Modelling Unit-level Evidence and Research Strategy (Progress Update 2007-08). Department for Transport (DfT), The Stationary Office, London.

DfT, 2008b. Transport Statistics Great Britain: 2008 edition. Department for Transport (DfT), The Stationary Office, London.

DLR, 2000. Databases with emissions profiles of civil jets, Measures for polluter-related pollution reduction in civil aviation. Deutsches Centrum fuer Luftraumfahrt (DLR), Friedrichshafen.

Dresner, S., 2005. Distributional, practical and political implications of carbon taxes and trading. UKERC Taxing and Trading Workshop, 3rd and 4th November Oxford. 
EC, 2002. Development of a Database System for the Calculation of Indicators of Environmental Pressure Caused by Transport, TRENDS main report. LAT, DTU, PSIAMTK and INFRAS for the European Commission, Brussels.

EDINA, 2006. Digimap mapping data (last accessed at http://edina.ac.uk/digimap/index.shtml on 20/03/2006). University of Edinburgh Data Library, Edinburgh.

EEA, 2000. COPERT III: Computer Programme to Calculate Emissions from Road Transport - Methodology and Emission Factors (Version 2.1), Technical report No 49. European Topic Centre on Air and Climate Change, European Environment Agency (EEA), Copenhagen.

EEA, 2005. EMEP/CORINAIR Emission Inventory Guidebook, 4th Edition, Technical report No 30. European Environment Agency, Copenhagen.

Ekins, P., Dresner, S., 2004. Green taxes and charges: reducing their impact on low-income households. Joseph Rowntree Foundation, York.

FAR and Germanwatch, 2005. The 'atmosfair' emissions calculator: Background Paper. Last accessed at http://www.atmosfair.de/fileadmin/user_upload/image4/atmosfair_calculator_04.pdf on 16/10/2005. forum anders reisen (FAR) and Germanwatch.

Fawcett, T., Bottrill, C., Boardman, B., Lye, G., 2007. Trialling personal carbon allowances, UKERC/RR/DR/2007/002, last accessed at http://www.eci.ox.ac.uk/research/energy/downloads/fawcett-pca07.pdf on 07/09/09. Environmental Change Institute, UK Energy Research Centre and SustainAbility, Oxford.

Fox, M., 1995. Transport planning and the human activity approach. Journal of Transport Geography 3, 105-116.

Go Ahead, 2005. OXFORD BUS COMPANY: ENVIRONMENTAL \& SOCIAL REPORT 2005, REVISED EDITION. The Go-ahead Group, Newcastle-upon-Tyne.

Greening, L.A., 2004. Effects of human behaviour on aggregate carbon intensity of personal transportation: comparison of 10 OECD countries for the period 1970-1993. Energy Econ. 26, 1-30.

Greening, L.A., Schipper, L., Davis, R.E., Bell, S.R., 1997. Prediction of Household Levels of Greenhouse-Gas Emissions from Personal Automotive Transportation. Energy 22, 449-460.

Hillman, M., Fawcett, T., 2004. How We Can Save the Planet. Penguin, London.

Hillman, M., Walley, A., 1983. Energy and personal travel: obstacles to conservation. Policy Studies Institute, London. 
Houghton, J.T., Ding, Y., Griggs, D.J., Noguer, M., van der Linden, P.J., Xiaosu, D., 2001. Climate Change 2001: The Scientific Basis, Part of the Working Group 1 Contribution to the Third Assessment Report of the International Panel on Climate Change. International Panel on Climate Change (IPCC), Cambridge University Press, Cambridge.

Hughes, P., 1994. Personal Transport and the Greenhouse Effect. Earthscan Publications Ltd, London.

IPPR, 2003. Putting the brakes on climate change: a policy report on road transport and climate change. Institute for Public Policy Research (IPPR), London.

Jackson, J., Li, Y., Passant, N., Thistlethwaite, G., Thomson, A., Cardenas, L., 2007. Greenhouse Gas Inventories for England, Scotland, Wales and Northern Ireland: 19902005. AEA Energy \& Environment, Harwell.

Jardine, C., 2005. Calculating the Environmental Impact of Aviation Emissions, Final Report to Climate Care. Environmental Change Institute, University of Oxford, Oxford.

JRC and CONCAWE EUCAR, 2006. Well-to-Wheels analysis of future automotive fuels and powertrains in the European context, Well-to-Wheels Report, version 2c, March 2007 (last accessed at http://ies.jrc.ec.europa.eu/WTW on 19/03/09). Joint Research Centre of the European Commission (JRC), The oil companies' European association for environment, health and safety in refining and distribution (CONCAWE) and European Council for Automotive Research and Development (EUCAR), Ispra, Italy.

Keay-Bright, S., Fawcett, T., 2005. Taxing and trading: Debating options for carbon reduction, Meeting report. UK Energy Research Centre, London.

Kennedy, P., 2003. A Guide to Econometrics, 5th edition, 5 ed. Blackwell Publishing Ltd., Oxford.

Korbetis, M., Reay, D.S., Grace, J., 2006. New Directions: Rich in CO2. Atmos. Environ. 40, 3219-3220.

Lee, M.S., McNally, M.G., 2003. On the structure of weekly activity/travel patterns. Transp. Res.: Part A: Pol. Practice 37, 823-839.

NETCEN, 2003. National Atmospheric Emissions Inventory (NAEI). NETCEN for the Department for the Environment, Food and Rural Affairs, Harwell.

Nilsson, M., Kuller, R., 2000. Travel behaviour and environmental concern. Transp. Res.: Part D: Transport Environ. 5, 211-234.

Ntziachristos, L., Samaras, Z., 1997. COPERT II - Computer Programme to Calculate Emissions from Road Transport, User's Manual. European Environmental Agency, Copenhagen. 
ONS, 2004. The impact of UK households on the environment through direct and indirect generation of greenhouse gases. Office for National Statistics (ONS), London.

ONS, 2005a. International Passenger Survey: 1980-2005. Office for National Statistics (ONS), London.

ONS, 2005b. Transport Statistics Bulletin: National Travel Survey 2004. Office of National Statistics, Transport Statistics: Department for Transport, London.

ONS, 2007. Transport Statistics Bulletin: National Travel Survey 2006. Office of National Statistics, Department for Transport, London.

Sausen, R., 2005. Aviation radiative forcing in 2000: An update on the IPCC (1999). Meteorologische Zeitschrift 14, 555-561.

Shine, K.P., Bernsten, T.K., Fuglestvedt, J.S., Sausen, R., 2005. Scientific issues in the design of metrics for inclusion of NOX in global climate agreements. Proceedings of the National Academy of Sciences 102, 768-773.

Stead, D., 1999. Relationships between Transport Emissions and Travel Patterns in Britain. Transport Policy 6, 247-258.

Stopher, P.R., 2000. Survey and Sampling Strategies, in: Hensher, D.A., Button, K.J. (Eds.), Handbook of Transport Modelling, First ed. Elsevier Science Ltd, Oxford.

Susilo, Y.O., Stead, D., 2007. Urban form, vehicle emissions and energy use of commuters in the Netherlands, Proceedings of the eceee 2007 Summer Study, Nice, France.

UNCED, 1992. Rio Declaration on Environment and Development, last accessed at http://www.unep.org/Documents/Default.asp?DocumentID=78\&ArticleID=1163 on 20/08/05. UNCED, Rio de Janeiro.

VCA, 1996. New Car Fuel Consumption and Emissions Figures: May 1996. Vehicle Certification Agency (VCA), Bristol.

Wit, R.C.N., Boon, B.H., van Velzen, A., Cames, M., Deuber, O., Lee, D., 2005. Giving wings to emission trading: Inclusion of aviation under the European emission trading system (ETS): design and impacts. CE Delft, Delft. 